\title{
Tribological Evolution of the Superficial Layer and the Effects of the Magnetic Field to a Non - conventional Treated Steel, During Wear Tests
}

\author{
CARMEN PENELOPI PAPADATU ${ }^{1}$, ANDREI VICTOR SANDU2,3,4*, MARIAN BORDEI ${ }^{1}$, IOAN GABRIEL SANDU2,5, SORIN CIORTAN ${ }^{1}$ \\ ${ }^{1}$ Dunarea de J os University of Galati, Faculty of Engineering, 111 Domneasca Str., 800008, Galati, Romania \\ ${ }^{2}$ Gheorghe Asachi Technical University of lasi, Faculty of Materials Science and Engineering, 41 D. Mangeron Blvd., 700050, Iasi, \\ Romania \\ ${ }^{3}$ Center of Excellence Geopolymer and Green Technology (CEGeoGTech), School of Materials Engineering, Universiti Malaysia \\ Perlis (UniMAP), Perlis, Malaysia. \\ ${ }^{5}$ Romanian Inventors Forum, 3 Sf. Petru Movila St., BI. L11, Sc. A., III/3, 700089, lasi, Romania
}

\begin{abstract}
The article focuses on the behavior of the non-conventional treated alloyed steel in magnetic field, during the dry wear tests. It is a review of the experimental tests from last years. The thermo-magnetic treatments have been applied before the application of a thermo-chemical treatment in plasma based on diffusion process. The study was made in order to improve the mechanical properties of the alloyed steel during the friction wear. Thermo-magnetic treatment applied before the plasma nitro-carburizing treatment improves the mechanical properties of the material especially in this case, for a steel that has a considerable content of Chromium (1.02\%). The behavior was studied using X-Ray diffractometry of the superficial layers during the dry friction of wear process. The wear tests used an Amsler machine, during three hours of wear tests. After each hour of the wear tests the samples have been analyzed. The diffractometric characteristics of the superficial layers obtained after a complex array of thermo-magnetic and thermo-chemical in plasma treatments, the phases distribution, the content of the superficial layers and the behavior of the steel during the wear through dry friction tests, have been considered as criteria.
\end{abstract}

Keywords: thermo-magnetic treatments; plasma nitro-carburizing; superficial layer.

Nitro-carburizing in plasma is a thermo-chemical process widely employed in the machine components production and metallurgical industry to mitigate any wear and corrosion damage in the material. These processes are strongly influenced by many different variables such as the steel composition, the nitrogen potential (range 0.8$35)$, the temperature of the treatment $\left(530^{\circ} \mathrm{C}\right)$, time $(8$ hours, in this case) [1]. The influence of such parameters affecting the nitrocarburized layers' thickness, layers' composition and diffractometry aspects were assessed.

Nitrocarburizing is a thermo-chemical process with diffusion, in which nitrogen, carbon, and to a very small degree, oxygen atoms, diffuse into the surface of the steel sample, forming a compound layer at the surface (a white layer) and - in the vicinity- the diffusion layer. This treatment is a variation of the case hardening process. It can't be neglected that the thermo-chemical nitrocarburizing treatment in plasma is a shallow case variation of the nitriding process and it is used only to provide an anti-wear resistance to the surface layer, and thus to improve the corrosion resistance.

The superficial layer of a nitrocarburized steel has a thickness of $0.2-0.35 \mathrm{~mm}$, depending on the nitrocarburizing duration or/and the thermo-magnetic treatment regimes applied, and it consists of the nitrides: $\varepsilon$ - phase with variable composition of carbon and nitrogen, depending on the steel grade or the atmosphere type, and unstable [2], or $\gamma^{\prime}$ - phase ( $\mathrm{Fe}_{-} \mathrm{N}$ )- in the case of nitriding, or a mixture which depends on the atmosphere and the steel grade composition [2,3].

Tribological properties during the friction and the wear processes are determined by the white layer. Under the white (compound) layer exists a diffusion area, which reaches deeper into the material, until approximately 0.1 $0.5 \mathrm{~mm}$. In the case of the wear dry tests the Normal Load
(Q) bearing capacity and fatigue strength are largely determined by the micro-hardness (Vickers) values and by the depth of the diffusion area, which can be observed by analyzing the microstructural aspects of the steel.

In the nitriding/nitro-carburizing configuration, the net flux of nitrogen necessary for the growth of the layer is in the growth direction. The influence of compositional and misfit-generated stresses on the morphological stability has been discussed qualitatively. For these reasons, in the present paper, a large attention has been devoted to monitoring and controlling the compound superficial white layers and their effect on mechanical properties [3-9]. The microstructural evolution of the compound layer produced by nitro-carburizing ferritic iron is much more complicated than in the case of nitriding [2]. The diffusion of two components exists, for nitrogen and carbon, and for the more complex meta-stable phase equilibrium of the ternary Fe-C-N system.

For example, in the literature have been mentioned that $\alpha-\mathrm{Fe}[\mathrm{N}, \mathrm{C}]$ phase has a Nitrogen content $[\%]<0.4$ and a Carbon content $[\%]<0.1[5,10-12] . \gamma-\mathrm{Fe}[\mathrm{N}, \mathrm{C}]$ Phase has a Nitrogen content $[\%]<10.3$ and a Carbon content $[\%]<$ 9.1[5, 10-12]. $\varepsilon-\mathrm{Fe}_{3}(\mathrm{~N}, \mathrm{C})_{1+\mathrm{K}}$ Phase which is Hexagonal close - packed Fe sublattice $N$ and $C$ ordered in octahedral interstices, has a Nitrogen content approx. $15-33 \%$ and a Carbon content until 8\% [16].

A more significant quantity of the chromium $(\mathrm{Cr})$ in the structure of the steel increases the thermo-magnetic treatment power and the results are the best. At the same time, the existence of the Chrome nitrides in the structure of the superficial layers after plasma nitrocarburizing treatment causes an increase of the corrosion resistance.

If the content of Chromium increases in the structure of the steel, the quantity of the residual austenite (Arez.) decreases in accelerated mode, while the quantity of the 
martensite (M) and, implicitly, the hardness of the steel, both of them increase more than in the case of the steel with approx. the same content of Carbon but with a lower Aluminum content. The magnetic field intensity implies the Magnetostriction existence and, together with the Carbon content, influence the properties. All of these factors have an important influence on the behavior of the steel during dry friction process. The break tendency of the steel decreases if apply a non-conventional treatment in magnetic field, similarly with this study. Magnetostriction determines local oscillations which can lead to local plastic deformations [3, 4, 6, 18-21]. Magnetostriction determines a reduction of the quantity of the residual austenite (Arez.), resulting a higher hardness of the material. We can have good mechanical and endurance characteristics $[3,16$, 17]. When a magnetic field is applied, the boundaries between the grains are changed, and the domains are rotated; both of these effects cause changes in the material's micro-volumes. This change in the magnetic domains of material determines changes in the materials dimensions as the consequence of the magnetocrystalline anisotropy, and that takes more energy to magnetize a crystalline material in one direction than in another. In the literature [3, 18], if a magnetic field is applied at an angle along the weaker axis of magnetization, the material will tend to rearrange its structure. Accordingly, the weaker axis is aligned with the field to minimize the free energy of the system. Different crystal directions were associated with different lengths. This effect induces a strain in the analyzed material.

\section{Experimental part}

For experimental Program have been used rollers (discs) as samples with $10 \mathrm{~mm}$ width. These samples (rollers) were taken from the steel, specifically a steel grade good for a machine parts construction, with the following chemical composition: $0.42 \% \mathrm{C}, 1.02 \% \mathrm{Cr}, 0.17 \% \mathrm{Mo}$, $0.68 \% \mathrm{Mn}, 0.22 \% \mathrm{Cu}, 0.33 \% \mathrm{Si}, 0.26 \% \mathrm{Ni}, 0.030 \% \mathrm{P}, 0.026$ $\% \mathrm{~S}$. The existence of the Molybdenum ( $\mathrm{Mo}$ ) content in the composition of the steel $(0.17 \%)$ implies the decreasing of the stiffening phenomenon. Aluminium is present in a very small quantity and can't influence the hardness of the steel. The outer diameter of the rollers has $40 \mathrm{~mm}$ and the inner diameter of the rollers has $16 \mathrm{~mm}$.

The first stage from the complex program of treatments consists of thermo-magnetic treatment. The treatment $\mathrm{t} 1$ represents a heating at $850{ }^{\circ} \mathrm{C}$, maintaining in furnace according with the dimensions of the samples, cooling in water followed by a heating at $580^{\circ} \mathrm{C}$, maintaining at this temperature and cooling in water. It is a classic treatment of improvement (a hardening and a higher tempering), without Magnetic field (Magnetic field intensity $\mathrm{H}=0$ ). The other treatment, t2, represents a heating process at 850 ${ }^{\circ} \mathrm{C}$, maintaining at this temperature according with the dimensions of the samples, cooling in water in strong alternative current (A.C.) of magnetic field followed by a heating process at $580^{\circ} \mathrm{C}$, with the cooling in water in strong A.C. magnetic field. Treatment $\mathrm{t} 3$ represents a heating process at $850{ }^{\circ} \mathrm{C}$ with cooling in water, in direct current (D.C.) of magnetic field followed by a heating process at $580^{\circ} \mathrm{C}$, with cooling in water in D.C. magnetic field [14, 17].

The second stage of the complex program of treatments consists on applying a plasma (ion) nitro-carburizing at $540{ }^{\circ} \mathrm{C}(7 \mathrm{~h})$, after thermo-magnetic treatment, applied at the different samples from the same steel grade considered. The treatments were noted such as: $\mathrm{Tl}=$ Tclassic $=\mathrm{t} 1$ + plasma nitro-carburizing; $\mathrm{T} 2=\mathrm{t} 2+$ plasma nitro-carburizing; $\mathrm{T} 3=\mathrm{t} 3$ + plasma nitro-carburizing. The nitro-carburized layers were revealed at room temperature by chemical etching with Nital ( $2 \%$ nitric acid in absolute ethanol).

The wear tests were made using an Amsler machine, roller on roller, taking one sliding degrees $(\xi=10 \%)$, for three hours. The outer diameter of the rollers was $40 \mathrm{~mm}$. The Moment of friction was $\mathrm{Mf}=45 \mathrm{daN} / \mathrm{mm}^{2}$. After each hour of wear test, the external diameter was measured and the diffractometric aspects were studied. The wear resistance of the rollers through dry friction, and the surface structure evolution for different parameters of testing regimes were determined.

\section{Results and discussions}

By analyzing the diffractometric fragments (see figures: 2,3 and 4), the variations of the quantities of the phases formed with alloying elements of the steel can be observed. These variations were determined by thermal/ thermo-magnetic treatments applied before the thermochemical treatment. The temperature of the thermochemical treatment ( plasma nitrocarburizing) is below the temperature of the thermo-magnetic ones, as to avoid microstructural modifications caused by the latter.

In table 1, the evolution of the phases and the characteristics from the superficial layers of the samples after plasma nitro-carburizing treatment and after each hour of wear tests, have been presented [3].

Following the repartition degrees of the phases for this material, it can be observed, that in the case of the application of the magnetic field-Alternative Current ( $\mathrm{H} 3=1300 \mathrm{~A} / \mathrm{m}$, intensity) during the cooling at the improvement processes applied before the plasma nitrocarburizing, the higher quantities of the hard phases for example, chromium carbide, or $\mathrm{Cr}_{2} \mathrm{~N}$, or Fe $\rightarrow$ (M)were obtained comparing with the quantities obtained in Table 1

WEAR PROCESS CHARACTERISTICS AND THE EVOLUTION OF THE PHASES IN THE WHITE LAYERS OF THE STEEL

\begin{tabular}{|c|c|c|c|c|c|c|c|c|c|c|c|c|}
\hline $\begin{array}{l}\text { Sample } \\
\text { Code }\end{array}$ & $\begin{array}{l}{[\%]} \\
\mathrm{I}_{\text {Fon }}(\mathrm{M}) \\
\left(44-45^{\circ}\right)\end{array}$ & $\begin{array}{l}{[\%]} \\
\mathrm{B}_{\mathrm{F} e z} \\
(\mathrm{M}) \sim \mathrm{c} / \mathrm{a}\end{array}$ & $\begin{array}{l}{[\%]} \\
I_{F \circ n(M)} \\
\left(82,5^{\circ}\right)\end{array}$ & $\begin{array}{l}{[\%]} \\
B_{211} \\
\sim \text { OII }\end{array}$ & $\begin{array}{l}{[\%]} \\
I_{C r N}\end{array}$ & $\begin{array}{l}{[\%]} \\
\mathrm{I}_{\mathrm{F} 03 \mathrm{CN}}\end{array}$ & $\begin{array}{l}{[\%]} \\
I_{C n 2 \mathrm{~N}}\end{array}$ & $\begin{array}{l}{[\%]} \\
\mathrm{I}_{\mathrm{Co} 3 \mathrm{~N}}\end{array}$ & $\begin{array}{l}{[\%]} \\
\mathrm{I}_{\mathrm{F} o 4(\mathrm{C}} \\
\mathrm{N})\end{array}$ & $\begin{array}{l}\Delta \mathrm{t} \\
{[\mathrm{h}]}\end{array}$ & $\begin{array}{l}\text { Treat- } \\
\text { ment }\end{array}$ & $\begin{array}{c}\text { Wear } \\
\text { Characteris-tics }\end{array}$ \\
\hline \multirow{4}{*}{$\begin{array}{l}\text { V1 } \\
\text { classic }\end{array}$} & 43.75 & 1.881 & 7.75 & 2.066 & 1.00 & 1.17 & 1.67 & - & 0.80 & 0 & T9 & \multirow{4}{*}{$\begin{array}{l}Q=150 \text { dal; } \\
\mathrm{d} 1=\mathrm{d} 2=40 \mathrm{~mm} \\
\mu=0,116 \\
\xi=10 \%\end{array}$} \\
\hline & 42.25 & 1.520 & 7.00 & 1.900 & 0.75 & 0.90 & 1.50 & - & 0.75 & 1 & T9 & \\
\hline & 43.00 & 1.500 & 8.25 & 2.050 & 0.50 & 1.25 & 1.50 & - & 0.50 & 2 & T9 & \\
\hline & 41.75 & 1.250 & 8.15 & 1.890 & 0.50 & 1.15 & 1.25 & - & 0.50 & 3 & T9 & \\
\hline \multirow{4}{*}{$\begin{array}{l}\text { V11 } \\
\text { (A.C.) }\end{array}$} & 62.75 & 1.721 & 14.50 & 1.779 & 2.00 & 1.50 & 1.75 & - & 1.75 & 0 & T11 & \multirow{4}{*}{$\begin{array}{l}Q=150 \text { daN; } \\
\mathrm{d} 1=\mathrm{d} 2=40 \mathrm{~mm} \\
\mu=0,116 \\
\xi=10 \%\end{array}$} \\
\hline & 68.75 & 1.746 & 10.50 & 1.826 & 1.85 & 0.75 & 1.65 & 0.5 & 1.65 & 1 & T11 & \\
\hline & 68.95 & 1.726 & 11.50 & 1.917 & 1.25 & 0.50 & 1.60 & - & 1.80 & 2 & T11 & \\
\hline & 108.75 & 1.669 & 18.00 & 2.264 & 1.25 & 0.45 & 1.50 & - & 1.80 & 3 & T11 & \\
\hline \multirow{4}{*}{$\begin{array}{l}\text { V10 } \\
\text { (D.C.) }\end{array}$} & 51.25 & 1.898 & 12.00 & 2.00 & 1.75 & 1.25 & 0.75 & 0.2 & 1.00 & 0 & T10 & \multirow{4}{*}{$\begin{array}{l}Q=150 \text { dali } \\
\mathrm{d} 1=\mathrm{d} 2=40 \mathrm{~mm} \\
\mu=0,116 \\
\xi=10 \%\end{array}$} \\
\hline & 51.50 & 1.763 & 9.00 & 1.897 & 1.00 & 0.75 & 0.50 & 0.4 & 0.85 & 1 & T10 & \\
\hline & 55.25 & 1.761 & 12.00 & 2.3 & 0.75 & 0.89 & 0.40 & 0.5 & 0.65 & 2 & T10 & \\
\hline & 69.25 & 1.565 & 14.00 & 2.37 & 0.75 & 1.00 & 0.20 & 0.7 & 0.50 & 3 & T10 & \\
\hline
\end{tabular}




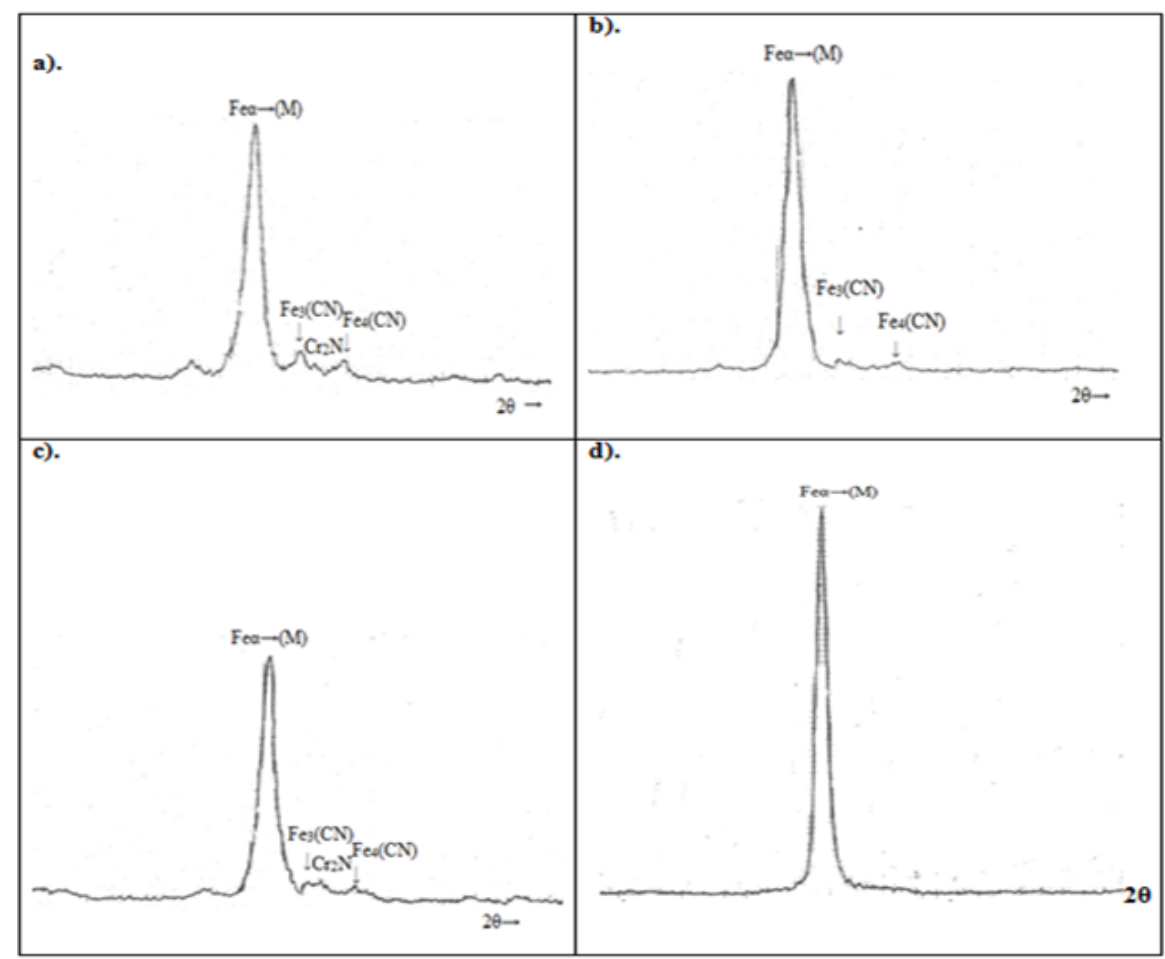

Fig. 1. Diffractometric spectrum evolution: a). Samples code V1 for treatment T1 (classic treatment), before the wear tests; b) Samples code V11, for unconventional treatment $\mathrm{T} 2$

(A.C. Magnetic field), before the wear tests; c). Samples code V11, for unconventional treatment T2 (A.C. Magnetic field), after three hours of wear tests; d). Samples code V11, for unconventional treatment $\mathrm{T} 2$, after three hours of wear tests
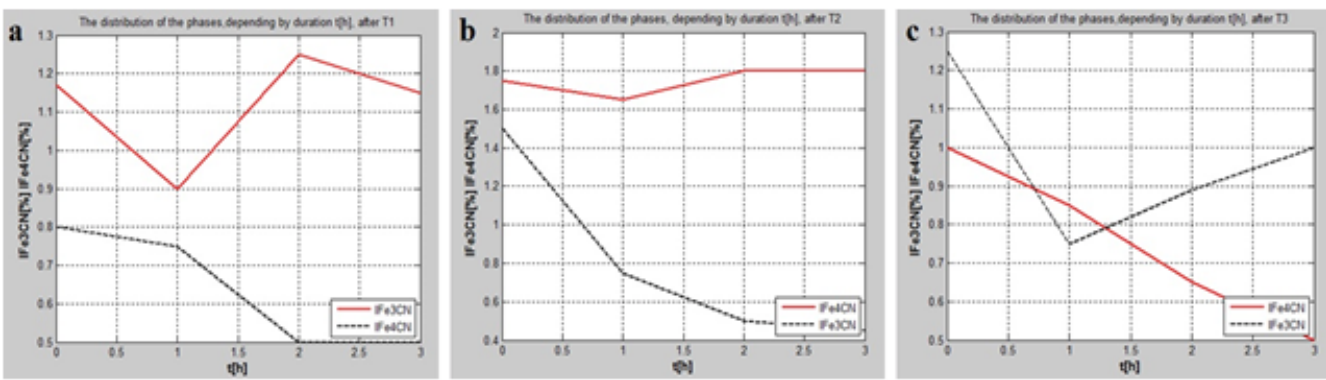

Fig. 2. Distribution of the phases on superficial layer, depending on the wear tests duration: a - for samples treated with $\mathrm{T} 1$; b - for samples treated with $\mathrm{T} 2$; c - for samples treated with T3
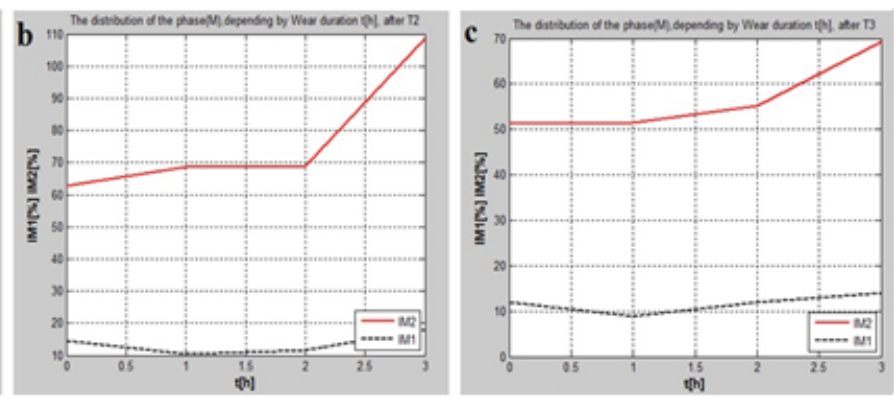

Fig. 3. Distribution of the phase Feá(M) on superficial layer, depending on the wear tests duration:

a - for samples treated with $T 1 ; b$ - for samples treated with $\mathrm{T} 2$ non-conventional treatment; $c$ for samples treated with T3 nonconventional treatment

the case of classic treatment. This is evidenced by the existence of the highest peaks (respectively, width of the diffraction lines) inside the following intervals: $41^{\circ} \div 45^{\circ}$ and $81^{\circ} \div 84^{\circ}$.

Figure la presents the diffractometric aspects in the case of classic treatment (T1). Figures $1 b$ and $1 c$ presents the diffractometric aspects in the case of nonconventional treatments (T2 and T3), before the wear tests [22, 23]. In figure $1 d$, the Fe $\alpha(M)$ quantity increased, after three hours of wear tests, compared with the initial state presented in figure $1 \mathrm{~b}$.

The variation of the phases distribution curves and some characteristics of the superficial layers unconventional treated were represented in the following figures.

Figures $2 \mathrm{a}, 2 \mathrm{~b}$ and $2 \mathrm{c}$ shows the distribution of the $\mathrm{Fe}_{3}(\mathrm{C}, \mathrm{N})$ and $\mathrm{Fe}_{4}(\mathrm{C}, \mathrm{N})$ phases after classic treatment and after nonconventional treatments in magnetic fieldAlternative Current (A.C.) respective, DirectCurrent(D.C.).

By comparing figures $3 a$ and $3 b$ we observe that the quantity of the $\mathrm{Fe}_{A}(\mathrm{CN})$ phase is greatest in the case of the non-conventional' treatment in magnetic field - Alternative Current (see T2 case). This $\mathrm{Fe}_{4}(\mathrm{CN})$ phase has a oscillated variation of the quantity (see the red diagrams) after every hour of the wear tests. $\mathrm{Fe}_{4}(\mathrm{CN})$ has the role to increases the corrosion resistances. So, in the case of T2 nonconventional treatment, the resistance of the wear process of the superficial layers is higher, compared with the other treatments, in the cases T1 and T3. After three hours of wear tests, the quantity of the $\mathrm{Fe}_{3}(\mathrm{CN})$ phase in the superficial layers decreased more in the case of the nonconventional treatment. We know that this phase causes fatigue of the superficial layer, possibly leading to cracks. In figure $3 b$, this phase $\mathrm{Fe}_{3}(\mathrm{CN})$ has a descending quantity. This fact leads to increase of the durability of the superficial layers non-conventional treated in magnetic field - A.C.

Figure 4 shows the distribution of the Fe $\alpha \rightarrow(M)$ on the superficial layers during three hours of the dry wear tests. We can observe the increase of the Martensite (M) quantity inside the superficial layers; this is a non-conventionally treatment in magnetic field. By comparing figures $4 a$ and $4 \mathrm{~b}$, we can see that the quantity of the Feo(M) phase is largest in the case of the non-conventional treatment in magnetic field - Alternative Current (T2 case) or Direct 

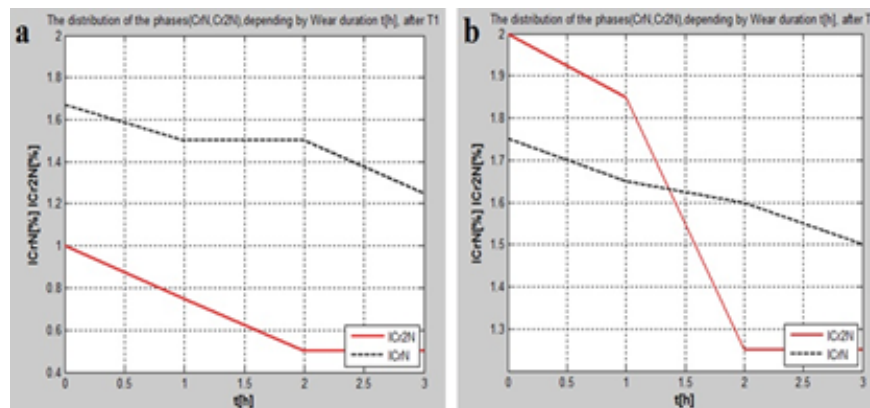

Current ( $T 3$ case). Martensite causes the increase of the microhardness values in the superficial layers.

Figure 5 shows the distribution of the Chrome nitrides in the superficial layers, depending on the treatments and the duration of the wear tests $(\Delta t)$. As in the case of the non-conventional treatment, we see that the Chrome nitrides quantities were increased, compared with the classic case (fig. 5a-Treatment T1).

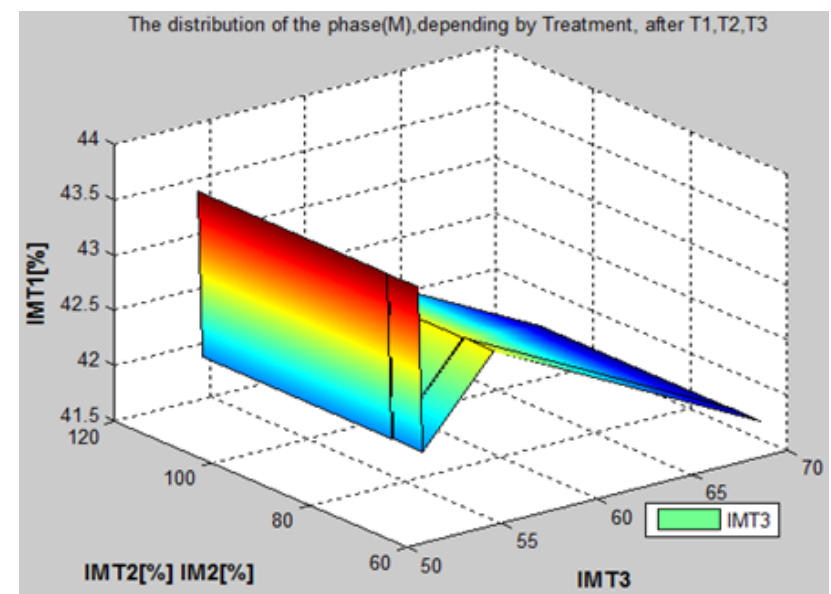

Fig.5. Distribution of the Fe $\alpha$ (M) phase quantity, depending on treatments, during three hours of wear process

The existence of Chrome-nitrides increases the corrosion resistance of the superficial layer. In this case, it can be mentioned that the non-conventional treatment in magnetic field, especially the T2 treatment, produces a better corrosion resistance than the classic treatment T1.

Figure 6 was shows the distribution of the phase Fe $\alpha \rightarrow$ (M), depending on the treatment, during three hours of wear process.

If we consider three hours of wear process and the follow ing notations: IM1 - the quantities of Fe $\alpha$ (M) phase, depending on the treatment T1; IM2 - the quantities of Fe $\alpha$ (M) phase, depending on the treatment T2; IM3 - the quantities of Fe $\alpha(M)$ phase, depending on the treatment T3

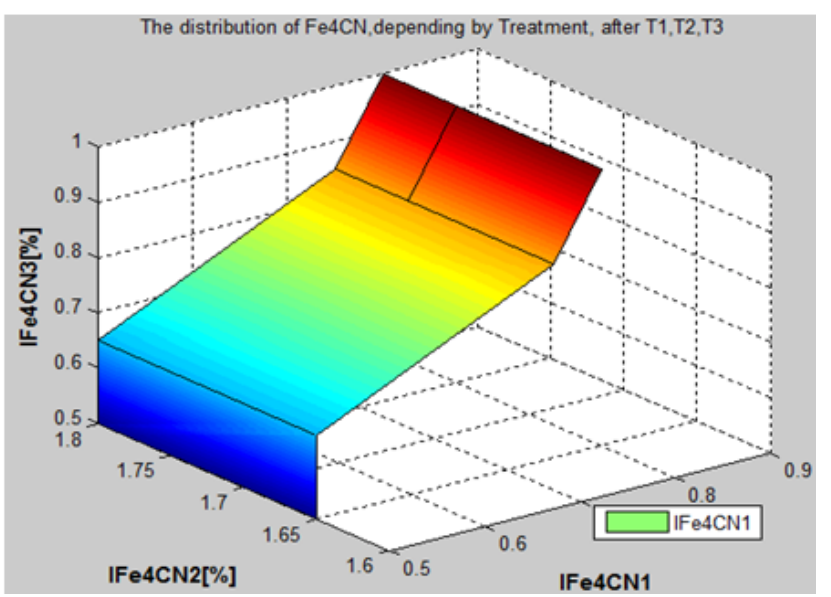

Fig.6. The distribution of the $\mathrm{Fe}_{4}(\mathrm{CN})$ phase quantity, depending on the treatments, corresponding to three hours of the wear tests

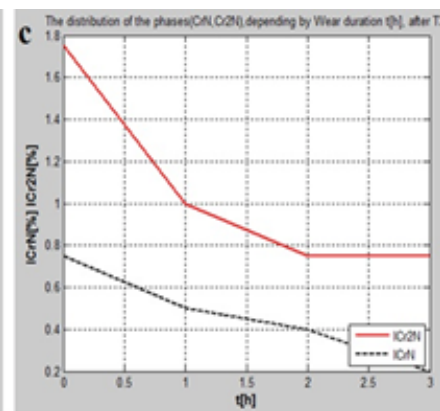

Fig. 4. Distribution of the

Chrome nitrides on the superficial layer, depending on the wear tests duration: $a$ - for samples treated with $\mathrm{T} 1, \mathrm{~b}$ - for samples treated with $\mathrm{T} 2$ (A. C.); C - for samples treated with T3

Figure 7 represents the distribution of $\mathrm{Fe}_{4}(\mathrm{CN})$ depending on the treatments, during three hours of the wear tests.

Figure 7 shows the evolution of the internal tensions (B211) of the second order, depending on the treatments, during three hours of the wear tests.

The following notations were considered: B1 - internal tensions of second order obtained in the case of the classic treatment (T1); B2 - internal tensions of second order obtained in the case of the nonconventional treatment (T2); B3 - internal tensions of second order obtained in the case of the nonconventional treatment (T3).

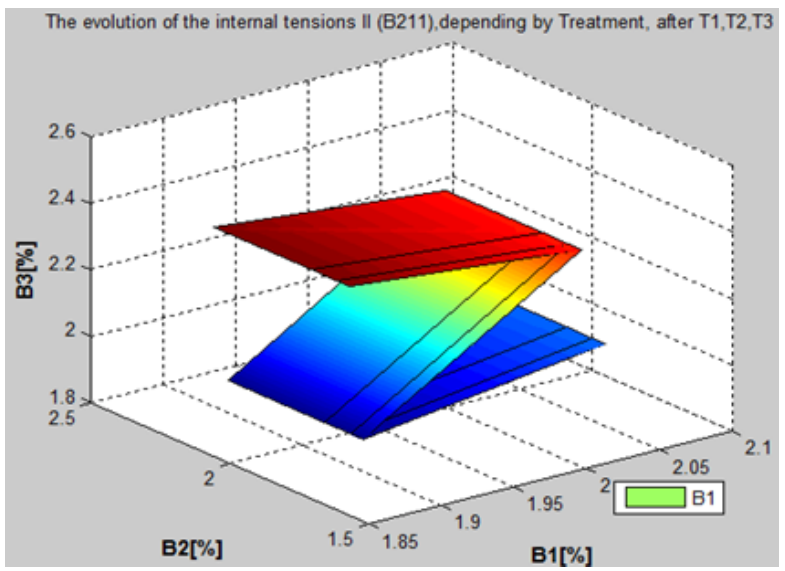

Fig. 7. The evolution of the internal tensions of second order (B211)
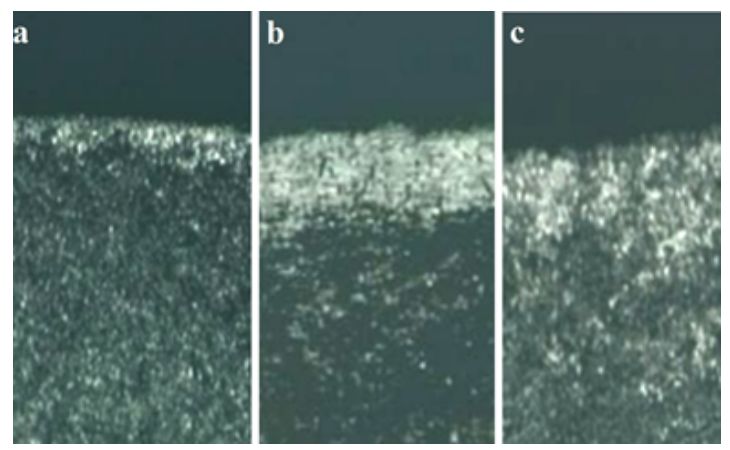

Fig. 8. Nitrocarburized superficial layer: a - T1 treatment $(\times 100)$ Nittal Attack $2 \%$;

b - T2 treatment $(\times 100)$ Nittal Attack $2 \%$; c- T3 treatment $(\times 100)$ Nittal Attack $2 \%$

Figures 8 presents the microstructural aspects, where: a represents displays the Microstructural aspect of a nitrocarburized $\left(7 \mathrm{~h} / 540^{\circ} \mathrm{C}\right)$ alloyed steel with $1.02 \% \mathrm{Cr}$ after the classic improvement treatment (T1), b shows a Microstructural aspect of a nitrocarburized $\left(7 \mathrm{~h} / 540^{\circ} \mathrm{C}\right)$ alloyed steel with $1.02 \% \mathrm{Cr}$ after the classic improvement treatment (T2), and respectively c presents a Microstructural aspect of a nitrocarburized $1.02 \% \mathrm{Cr}$ alloyed steel $\left(7 \mathrm{~h} / 540^{\circ} \mathrm{C}\right)$ after the thermo-magnetic treatment - Direct Current(T3). 


\section{Conclusions}

The first direction of the research was to increase the mechanical characteristics through the thermo-magnetic treatment and thermo-chemical treatment with diffusion applied under the temperature of the thermo-magnetic treatment.

Through this research direction were studied:

a). Improving the durability of the superficial layers of the steel during the friction process through the applying of the thermo-magnetic treatment on the side part of the samples. The changes induced by magnetic field determined the changes of the mechanical characteristics and structural changes from thermo-chemical treated layers of the steel.

b). Continuity of the thermochemically treated layer subjected to the wear tests and checking the results.

c). Ways to eliminate the delamination of the superficial layers of the steel.

The magnetic field applied during the improvement treatment before plasma nitrocarburizing changes the kinetics, decreasing the quantity of residual Austenite (Arez), while increasing the Martensite (M) quantity. As such, the hardness of the steel increases after thermomagnetic treatments, and the wear resistance of the superficial layers after nitrocarburizing process applied after thermo-magnetic treatments increased considerably.

In the case of the non-conventional treatment, the chrome nitrides quantities were increased, compared with the classic case. In this case, the corrosion resistance of the superficial layer increased.

It has been proved that after three hours of wear tests, the quantity of the $\mathrm{Fe}_{3}(\mathrm{CN})$ phase in the superficial layers decreases more in the case of the non-conventional treatment, and it leads to a decrease in cracking susceptibility.

The increase of the $\mathrm{Fe}_{4}(\mathrm{CN})$ phase quantity improved the wear resistance of the superficial layers nonconventionally treated, before the nitrocarburizing treatment.

This study has shown that the nitro-carburizing treatment applied to carbon steel enriched in chromium is adapted in order to improve the superficial layer of the steel treated nonconventionallyin a magnetic field. The nonconventional treatment in magnetic field -Alternative Current (T2) applied before the plasma nitro-carburizing treatment, influenced and improved the tribological properties of the superficial layers of the steel.

\section{References}

1.CAVALIERE, P., PERRONE, A., SILVELLO, A., Engineering Science and Technology, an International J ournal, 19, 2016, p. 292.
2.MITTEMEIJ ER, E.J ., Steel Heat Treating Fundamentals and Processes in J. Dossett, G.E. Totten (Eds.), ASM Handbook, Volume 4A, 2013.

3.PAPADATU, C.P., Researches on improving the properties and reliability of some steel grades used for manufacturing metallurgical equipment, PhD.Thesis, 2005, Dunarea de Jos University of Galati, Romania.

4.PAPADATU, C.P., , Annals of Constanta Maritime University,19, 2013, p. 151.

5.WRIEDT, H.A., ZWELL, L., Trans. AIME, 224, 1962, p. 1242.

6.PAPADATU, C.P., SANDU, A.V., BORDEI, M., SANDU, I.G., Rev. Chim., (Bucharest), 68, no. 4, 2017, p. 675.

7.ORECNY, M., BURSAK, M., VINAS, J., Metalurgija, 54, 2015, p. 191. 8.LIU, L., SHEN, H.H., LIU, X.Z., GUO, Q., MENG, T.X., WANG, Z.X., YANG, H.J., LIU, X.P., Applied Surface Science 388, 2016, p. 103.

9.LI, B., SHEN, Y.F., HU, W.Y. Applied Surface Science, 274, 2013, p. 356.

10.FERGUSON, P., JACK, K.H., Quench-Aging and Strain-Aging of Nitrogen-Ferrite, Proc. Heat Treatment ' 81 , The Metals Society, London, 1981, 158-163.

11.CHENG, L., BOTTGER, A., de KEIJSER, T.H., MITTEMEIJ ER, E.J ., Scr. Metall. Mater., 24, 1990, p. 509.

12.ONINK, M. BRAKMAN, C.M. TICHELAAR, F.D. MITTEMEIJ ER, E.J .. van der ZWAAG, S., Scr. Metall. Mater., 29, 1993, p. 1011.

13.PAPADATU, C.P., BORDEI, M., Advanced Materials Research, 1143, 2017, p. 174.

14.van GENDEREN, M.J., BOTTGER, A., CERNIK, R.J., MITTEMEIJER, E.J., Metall. Trans. A, 24, 1993, p. 1965.

15.SOMERS, M.A.J., van der PERS, N.M., SCHALKOORD, D., MITTEMEIJER, E.J., Metall. Trans. A, 20, 1989, p. 1533.

16.LIAPINA, T., Leineweber, A., MITTEMEIJER, E.J., KOCKELMANN, W., Acta Mater., 52, 2004, p. 173.

17.VILLARS, P., CALVERT, L.D., Pearson's Handbook of Crystallographic Data for Intermetallic Phases, American Society for Metals, Vols. 1-3. Metals Park, ISBN: 087170217 7, Ohio, 1986.

18.VONSOVSKI, S.V., Modern Theory of Magnetism, Technical Publishing House, Bucharest, 1956.

19.STEFANESCU, I., Contributions on the study of the influence of thermo-magnetic treatments on the Pitting wear for RUL1 Steel bearings, PhD. Thesis, Gheorghe Asachi Technical University of Iasi, 1982.

20.PAPADATU, C.P., Experimental studies regarding wear processes through dry friction of the superficial layer for an unconventional treated steel, IOP Conference Series: Materials Science and Engineering, 174, 2017, Article no. 012014.

21.J AMES, R.D., WUTTIG, M., Philosophical Magazine A, 77, 1998, p. 1273.

22.PAPADATU, C.P., SANDU, A.V., BORDEI, M., SANDU, I., Rev. Chim. (Bucharest), 68, no. 10, 2017, p. 2329.

23.BORDEI, M., SANDU, A.V., PAPADATU, C.P., SANDU, I.G., Rev.Chim. (Bucharest), 69, no. 3, 2018, p. 632.

$\overline{\text { Manuscript received: } 11.04 .2018}$ 